\title{
Tissue Doppler, Strain and Strain Rate in ischemic heart disease "How I do it"
}

\author{
Razvan O Mada, Jürgen Duchenne and Jens-Uwe Voigt ${ }^{*}$
}

\begin{abstract}
Echocardiography is the standard method for assessing myocardial function in patients with ischemic heart disease. The acquisition and interpretation of echocardiographic images, however, remains a highly specialized task which often relies entirely on the subjective visual assessment of the reader and requires therefore, particular training and expertise. Myocardial deformation imaging allows quantifying myocardial function far beyond what can be done with sole visual assessment. It can improve the interpretation of regional dysfunction and offers sensitive markers of induced ischemia which can be used for stress tests. In the following, we recapitulate shortly the pathophysiological and technical basics and explain in a practical manner how we use this technique in investigating patients with ischemic heart disease.
\end{abstract}

Keywords: Echocardiography, Deformation imaging, Tissue Doppler, Speckle tracking, Strain, Strain rate, Myocardial ischemia

\section{Background}

Assessing the impact of ischemic heart disease on cardiac function is one of the key tasks of routine clinical echocardiography. At virtually any stage of the disease process, echocardiography is of diagnostic or prognostic value, guiding further therapeutic decisions. The careful observation of global and regional ventricular function and morphology in resting images, allows describing and distinguishing acute ischemia, scar and infarct related remodeling while stress echocardiographic methods may be used to assess the severity of coronary stenosis or to identify viable myocardium. Offering this wealth of information, echocardiography has become an indispensable tool in managing patients with coronary artery disease.

The acquisition and interpretation of echocardiographic images, however, remains a highly specialized task which requires knowledge, skills and experience. Not all echocardiographic parameters are quantifiable. Moreover, typical echocardiographic tasks, such as the evaluation of regional myocardial dysfunction in ischemic heart disease, rely entirely on the subjective assessment of the reader and require therefore particular training and expertise [1-4].

\footnotetext{
* Correspondence: jens-uwe.voigt@uzleuven.be

Department of Cardiovascular Diseases, University Hospital Gasthuisberg, Catholic University Leuven, Herestraat 49, 3000 Leuven, Belgium
}

Tissue Doppler and speckle tracking based myocardial deformation imaging allows quantifying myocardial function far beyond what can be done with sole visual assessment. In the following, we would like to explain how we use this technique in investigating patients with ischemic heart disease.

\section{How to measure myocardial function}

Information on the technical and basic clinical applications of echocardiographic deformation imaging may be found elsewhere [5-7]. In short, regional myocardial function can be assessed by measuring strain or strain rate. Velocity and displacement are not suited for this task. Strain is defined as the fractional change in length of a myocardial segment relative to a baseline length and is expressed as percentage. Strain rate is the temporal derivative of strain and provides information on the speed at which the deformation occurs, expressed as $\left[\mathrm{sec}^{-1}\right]$. In clinical use, the complex three-dimensional deformation of the heart is commonly described by either its longitudinal (LS), circumferential (CS) or radial strain (RS) components ("normal strain components"). There are two main echocardiographic modalities for the assessment of myocardial deformation: tissue Doppler imaging (TDI) or speckle-tracking imaging (STI) (see also Tables 1 and 2). 
Table 1 Comparison of recommended steps for tissue Doppler and speckle tracking based deformation imaging

\begin{tabular}{|c|c|c|}
\hline & Tissue Doppler & Speckle tracking \\
\hline \multirow[t]{3}{*}{$\begin{array}{l}\text { Image } \\
\text { acquisition }\end{array}$} & $\begin{array}{l}\text { - TDI images with insonation angle }<15^{\circ} \text { (single wall acquisition if } \\
\text { needed) and adequate velocity scale (to avoid aliasing) }\end{array}$ & $\begin{array}{l}\text { - Optimized 2D images avoiding foreshortening and stationery } \\
\text { artefacts (reverberation) }\end{array}$ \\
\hline & -Frame rate $>100 \mathrm{fps}$ (ideally $>140 \mathrm{fps}$ ) & - Frame rate: $40-80$ fps \\
\hline & - Acquire spectral Doppler traces of mitral and aortic valve for timing & $\begin{array}{l}\text { - Acquire a spectral Doppler trace at least of the aortic valve as } \\
\text { backup for timing }\end{array}$ \\
\hline \multirow[t]{6}{*}{$\begin{array}{l}\text { Image } \\
\text { analysis }\end{array}$} & $\begin{array}{l}\text { - Measure aortic and mitral valve opening and closure in order to } \\
\text { define cardiac phases }\end{array}$ & \\
\hline & -Order of image analysis: arbitrary & $\begin{array}{l}\text { - Start analysis with the apical long axis view in order to define } \\
\text { aortic valve closure. Use Doppler derived data if needed. }\end{array}$ \\
\hline & $\begin{array}{l}\text { - Set the region of interest (ROI) shape and size oval somewhat } \\
\text { smaller than the wall thickness. Position the needed number of } \\
\text { ROls it in the middle of the segments to be analysed. Track ROI } \\
\text { position if needed. }\end{array}$ & $\begin{array}{l}\text { - Contour the myocardium according to the procedure } \\
\text { proposed by the vendor. Avoid including the bright } \\
\text { pericardium. }\end{array}$ \\
\hline & - Evaluation of curve quality. Repositioning of the ROI if needed. & $\begin{array}{l}\text { - Careful visual control of the proposed tracking. Repositioning } \\
\text { of the contours if needed. Exclusion of suboptimally tracked } \\
\text { segments if re-contouring is unsuccessful. }\end{array}$ \\
\hline & - Shape analysis of the curves & - Shape analysis of the curves \\
\hline & - Measurement of peak values and further post-processing if needed & $\begin{array}{l}\text { - Measurement of peak values and further post-processing if } \\
\text { needed }\end{array}$ \\
\hline
\end{tabular}

\section{Tissue Doppler derived deformation}

TDI is the classic approach to measure deformation in echocardiographic images [8]. From TDI data, strain rate can be simply derived by calculating the regional velocity gradient. By integration of the latter, strain is obtained. Major advantages of TDI derived strain measurements are the very high temporal resolution and the relative robustness if image quality is limited. After some training, curves are easy to interpret and allow a good distinction between good quality data and artefacts. For simple curve shape analysis in clinical use, no post-processing is needed since curves are readily available by just moving the mouse pointer over the myocardium. Disadvantages comprise the angle dependency of the data and the need for training and experience when advanced data handling and interpretation are needed.

\section{Speckle tracking derived deformation}

STI is a newer approach to assess myocardial deformation [9]. It relies on detecting features (mostly "speckles") in 2D greyscale images the displacement of which is measured. Velocity, strain and strain rate is then derived from the displacement information. Speckles can be tracked in any direction within the image plane which offers new options for motion and deformation analysis compared to the one-dimensional TDI method. STI depends strongly on good image geometry and quality, both of which are often difficult to achieve in routine clinical practice. The

Table 2 Advantages and limitations of tissue Doppler and speckle tracking based deformation imaging

\begin{tabular}{|c|c|c|}
\hline & Advantages & Limitations \\
\hline \multirow{6}{*}{$\begin{array}{l}\text { Tissue } \\
\text { Doppler }\end{array}$} & \multirow{6}{*}{$\begin{array}{l}\text { - High temporal resolution } \\
\text { - Robust in case of limited image quality } \\
\text { - Easy recognition of artefacts, easy assessment of data quality } \\
\text { - Fast qualitative analysis: curves readily available by moving the mouse pointer } \\
\text { over the myocardium (no post- processing needed) }\end{array}$} & - Dedicated image acquisition needed. \\
\hline & & - One dimensional: measures deformation along \\
\hline & & the ultrasound beam direction \\
\hline & & - Noisy data, sensitive to stationary artefacts \\
\hline & & $\begin{array}{l}\text { - Region of interest must be tracked to keep the } \\
\text { same position within the myocardium }\end{array}$ \\
\hline & & - Training needed \\
\hline \multirow{7}{*}{$\begin{array}{l}\text { Speckle } \\
\text { tracking }\end{array}$} & \multirow{7}{*}{$\begin{array}{l}\text { - Standard 2D images used for analysis } \\
\text { - Two-dimensional analysis possible } \\
\text { - Less noisy data } \\
\text { - Very user friendly } \\
\text { - Easy post-processing, wealth of graphical displays } \\
\text { - Highly automated extraction of derived parameters }\end{array}$} & - Lower temporal resolution \\
\hline & & - Strong dependence on image quality \\
\hline & & - Intensive regularization and drift correction with \\
\hline & & limited options for user interaction \\
\hline & & - Difficult assessment of data quality \\
\hline & & $\begin{array}{l}\text { - Intervendor differences in parameter definitions } \\
\text { and measurement algorithms }\end{array}$ \\
\hline & & - Need for training underestimated \\
\hline
\end{tabular}


need for good spatial resolution (i.e. high line density) limits the frame rate at which grey scale data can be acquired, leading to a lower temporal resolution of STI data. Modern analysis software offer many display options for tracking derived parameters. Besides the classic display of colour overlays, curves and curved M-modes, tracking results from different image planes can be combined and displayed in a bull's eye format which allows a fast and easy assessment of any tracking derived parameter (Figure 1) [10]. Currently, global longitudinal strain (GLS) emerges as new routine measure of ventricular function. It has been shown to be a robust and reproducible parameter, superior to classical ejection fraction (EF) measurement, probably due to the largely automated assessment and extensive spatial averaging. Inter-vendor differences in strain measurements must be considered. A joint task force of EACVI, ASE and Industry has recently prepared a consensus document for standardized STI based deformation imaging [11].

\section{Which function changes can we expect? Load dependence}

Functional imaging shows motion and deformation of the myocardium within the image plane. Any change in perfusion or the underlying metabolism of the myocardial fibres will remain invisible unless it affects their contractile state. Further, imaging cannot measure pressures or forces and is, thus, "blind" to loading conditions. Any observed myocardial deformation is consequently a product of the contractile state of the myocardial fibres, modulated by pre- and afterload. It is therefore important to understand, that all findings in functional cardiac imaging do not directly relate to myocardial contractility, but must be interpreted in the context of wall thickness, chamber geometry and loading conditions.

\section{Ischemic function changes}

The imbalance between oxygen demand and supply results in an impairment or loss of contractile function and, subsequently, cell death. Transient ischemia will cause reversible regional dysfunction. Even without structural damage, however, the dysfunction may last for hours after an ischemia which is called "stunning" $[12,13]$. A chronic reduction of coronary flow leads to a proportional myocardial dysfunction named "hibernation". Hibernating myocardium may also recover completely after restoration of blood flow, but degenerative changes and persistent dysfunction may occur after longer malperfusion [14]. Coronary occlusion lasting more than a few minutes results in irreversible myocardial injury with later scar formation [15]. Cardiac remodeling will occur depending on the amount of myocardial loss $[16,17]$.

The particular anatomy of the coronary arteries and the higher extravascular pressure make the subendocardial region most vulnerable to ischemia. Dysfunction will therefore firstly occur in the subendocardial fibres [18]. To which extend layer-specific (dys-)function can be evaluated by echocardiography, remains to be determined.

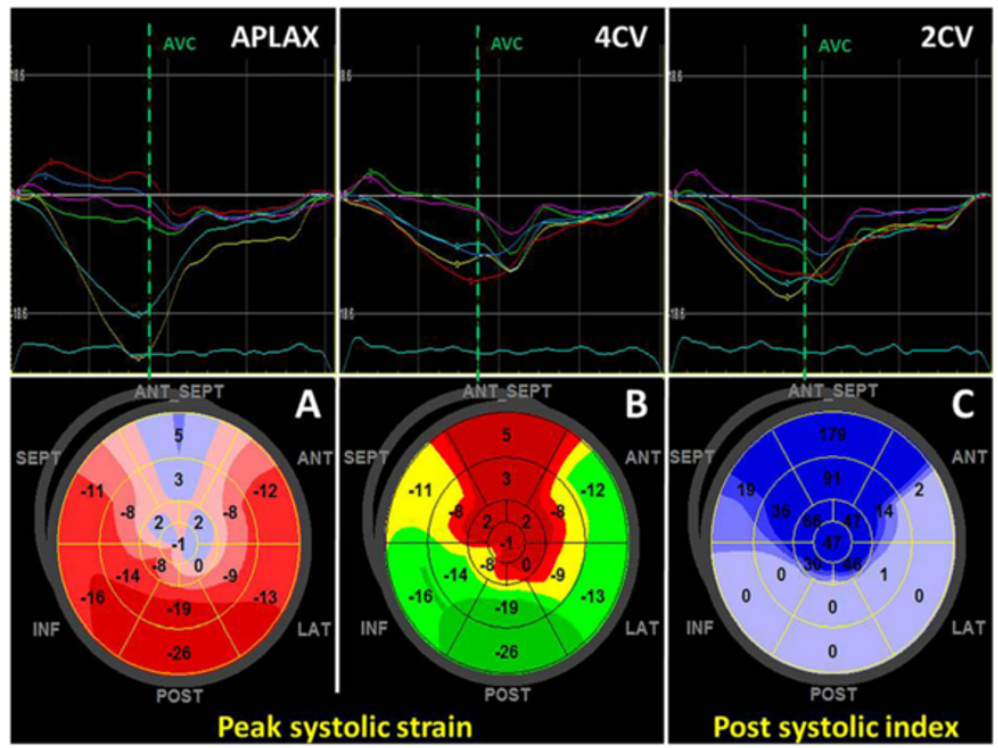

Figure 1 Speckle tracking based strain analysis in a patient with myocardial infarction. Upper panels: physiologic and pathologic segmental strain curves from the three apical standard views. Lower panels: bull's eye displays of the regional longitudinal strain; $\mathbf{A}$ and $\mathbf{B}$, peak systolic strain in two different colour maps; $\mathbf{C}$, post systolic index. Note the clear delineation of the anteroseptal infarct area. AVC - aortic valve closure; APLAX, 4CV, 2CV - apical long axis, four- and two-chamber view. 
Functional imaging is blind to stenosis of the epicardial vessels unless regional dysfunction develops due to ischemia. Pharmacological, physical or electrical stress tests are needed to induce such ischemia and belong, therefore, to the standard armamentarium of echocardiography in the clinical setting of ischemic heart disease $[4,19,20]$.

\section{Characteristic deformation patterns in disease}

Two principal changes can be observed with deformation imaging.

Type 1: The reduction in systolic strain indicates myocardial dysfunction, but may also be attributed to changes in loading conditions or ventricular geometry. The reliable detection of abnormal strain amplitudes requires a robust and reproducible measurement method. Under clinical conditions, the variability of both regional tissue Doppler and speckle tracking measurements is relatively high, which makes regional strain amplitude measurements currently less suited for routine use. This is in contrast to global strain measurements which have been shown to be reproducible and robust measures of global ventricular function, superior to classical EF measurements, probably due to the largely automated assessment and extensive spatial averaging [21].

Type 2: Regional inhomogeneities of myocardial activation and/or contractility can alter the temporal sequence of shortening and lengthening of the myocardium. In ischemia, not only the amplitude of shortening is reduced, but also onset and duration of fibre contraction are altered, which leads to a characteristic shortening or thickening of the myocardium after aortic valve closure. This so-called "post-systolic shortening" (PSS) or "post-systolic thickening" is a sensitive and specific feature of developing ischemia if a normal baseline examination is available $[22,23]$. If found under resting conditions, it is a sensitive but unspecific sign of regional dysfunction of any cause (scar, dyssynchrony, etc.) [24,25]. It must be noted, that PSS of a minor extend can be found in normal hearts, particularly at the apex and base of the inferior, septal and anteroseptal walls (Figure 2) [24].

\section{"How I do it" - Practical approaches in particular situations \\ Chronic ischemic disease}

Patients with myocardial damage after myocardial infarction will usually present changes in global and regional function, both of which need to be described and followed. In these patients, a speckle tracking based analysis can be most easily integrated in the clinical routine.

\section{Data acquisition}

Three standard grey scale image loops, with settings balanced for both spatial and temporal resolution (ca. 40-80 frames per second), covering the LV and including the mitral and aortic valve should be stored. Care must be taken that the LV is not foreshortened and that reverberation artefacts (bright, wedge-shaped, stationery artefacts) on the edges of the image sector are avoided. A clear artefact free display of the apex is desired. We acquire three consecutive heart beats, avoiding extrasystoles. In addition, a PW- or CW-Doppler trace of the LVOT is useful to obtain timing information.
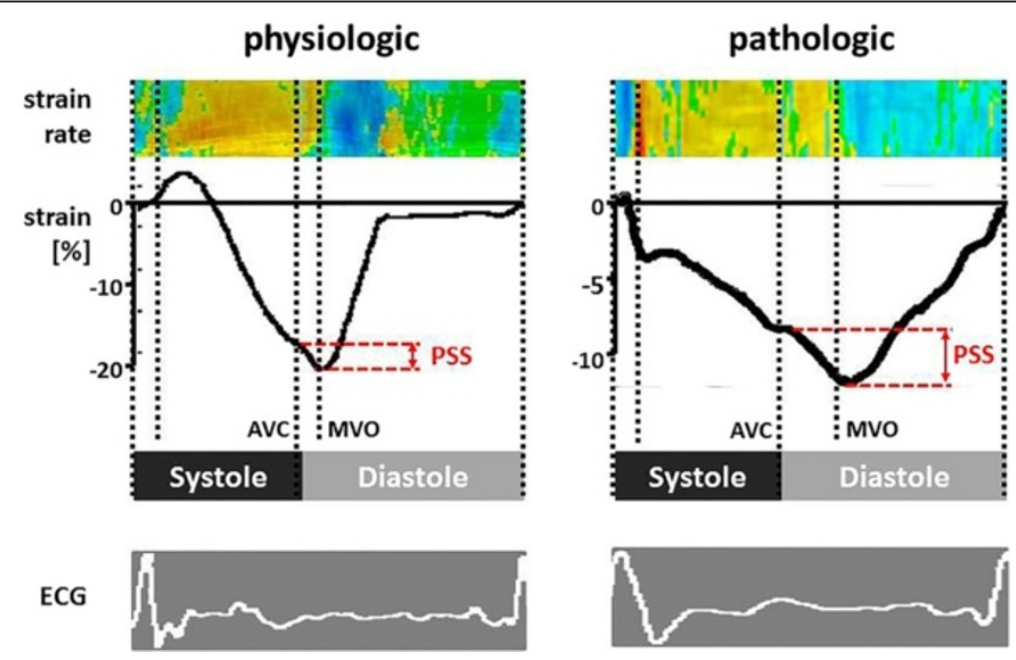

Figure 2 Colour coded strain rate curved M-modes (top) and strain curves (middle) in 2 myocardial segments both showing postsystolic shortening (PSS). Left panel: physiologic PSS in an apical septum of a normal heart. Peak systolic strain exceeds -18\% and PSS is less than $20 \%$ of systolic shortening. Right panel: pathologic PSS in a partially scarred segment post infarction. Peak systolic strain is reduced to $-10.1 \%$ while post systolic strain is increased to $39 \%$ of systolic strain. AVC - Aortic valve closure; MVO - mitral valve opening. (modified from Voigt et al. [22], with permission). 


\section{Data analysis}

First, the four- and two-chamber images are analyzed with an automated, tracking based EF measurement algorithm. Depending on the software used, this can be fully automatic or semi-automatic with the user indicating the initial endocardial contour. Care must be taken to check the tracking quality, i.e. how well the tracking line follows the endocardial motion. Software which do not allow this step should not be used. This procedure results in a set of volumetric measurements (volumes, ejection fraction, stroke volume, cardiac output) which is reported in the protocol of the examination (Figure 3).

Secondly, after manually defining aortic valve closure through direct visualisation in the apical three-chamber view or by using spectral Doppler data as alternative, myocardial speckle tracking of all three apical image planes is performed. This is again a fully- or semiautomated process as described above and the quality of tracking needs to be checked in a similar way. The position of the tracking region depends on the vendor specific software and may comprise just the endocardium and epicardium or the full wall. Accordingly, expected strain values will differ. The largest body of evidence exists for full wall strain measurements, but several companies do also/only offer endocardial strain. This analysis delivers GLS as average of all three apical views, which is then reported in our echo protocol. Further, the bull's eye view of LV systolic strain can be used to support regional function analysis. Special colour maps, e.g. for the post-systolic index, i.e. PSS relative to the peak strain, are particularly sensitive for regional dysfunction (Figure 1).

\section{Acute ischemia}

This is usually an emergency room scenario where an immediate coronary intervention has highest priority. The echocardiographic examination should therefore be limited to the necessary minimum which is needed to clarify remaining clinical questions. Conclusions will be usually drawn from the immediate visual analysis of the image data.

\section{Data acquisition and analysis}

A documentation of the three apical views is a matter of seconds and should be attempted. It allows a later offline speckle tracking based analysis as described above, which can serve as baseline investigation to follow the course of the patient (Figure 4).

\section{Ischemia testing}

Ischemia testing aims at detecting transient regional dysfunction during an exercise or pharmacological stress

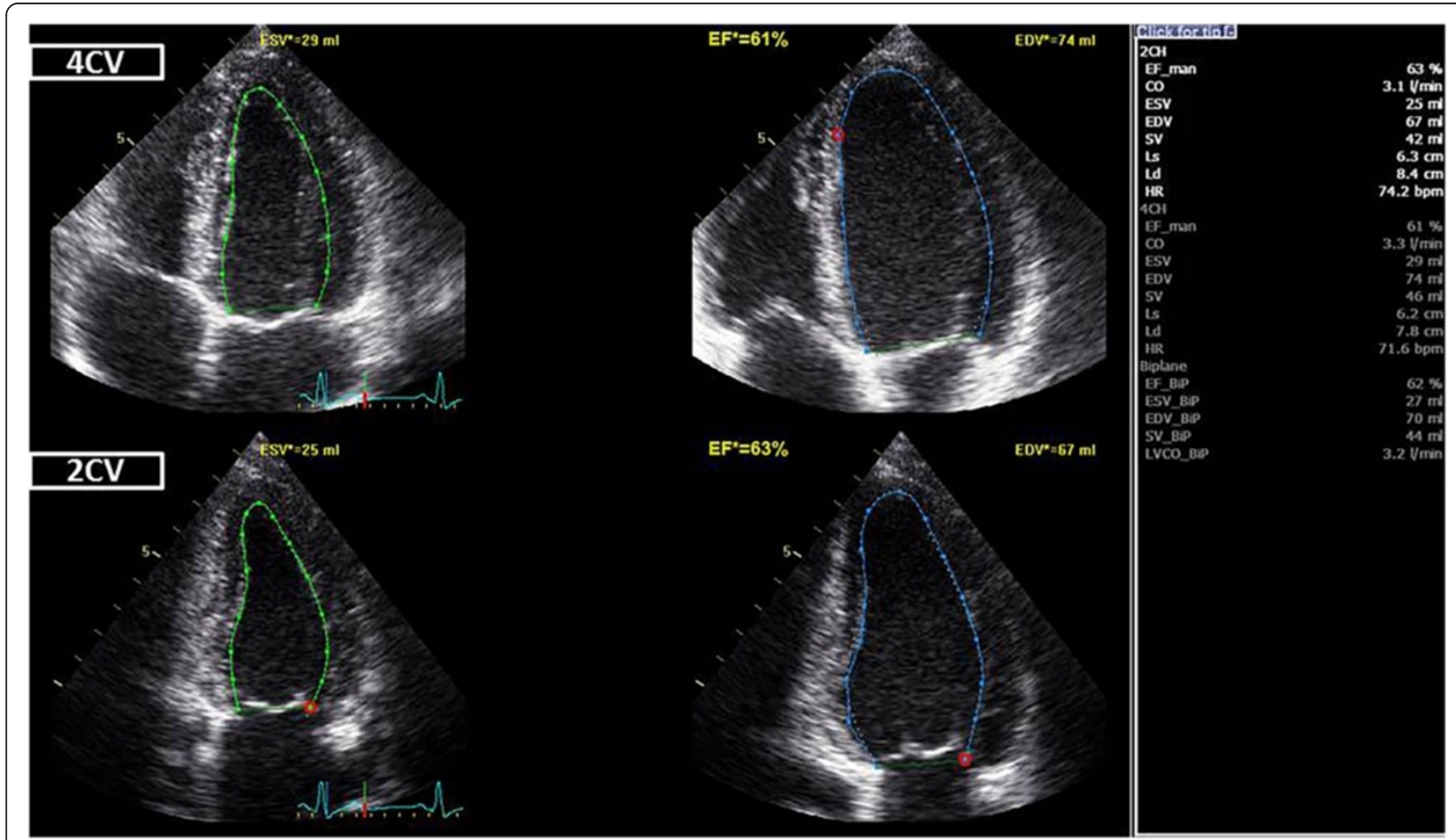

Figure 3 Tracking based ejection fraction measurement. Fully automated delineation and tracking of the endocardial contour throughout the cardiac cycle allows a fast and reproducible bi-plane assessment of global LV function and volumes. EF - ejection fraction; CV - chamber view; EDV - end-diastolic volume; ESV - end-systolic volume. 

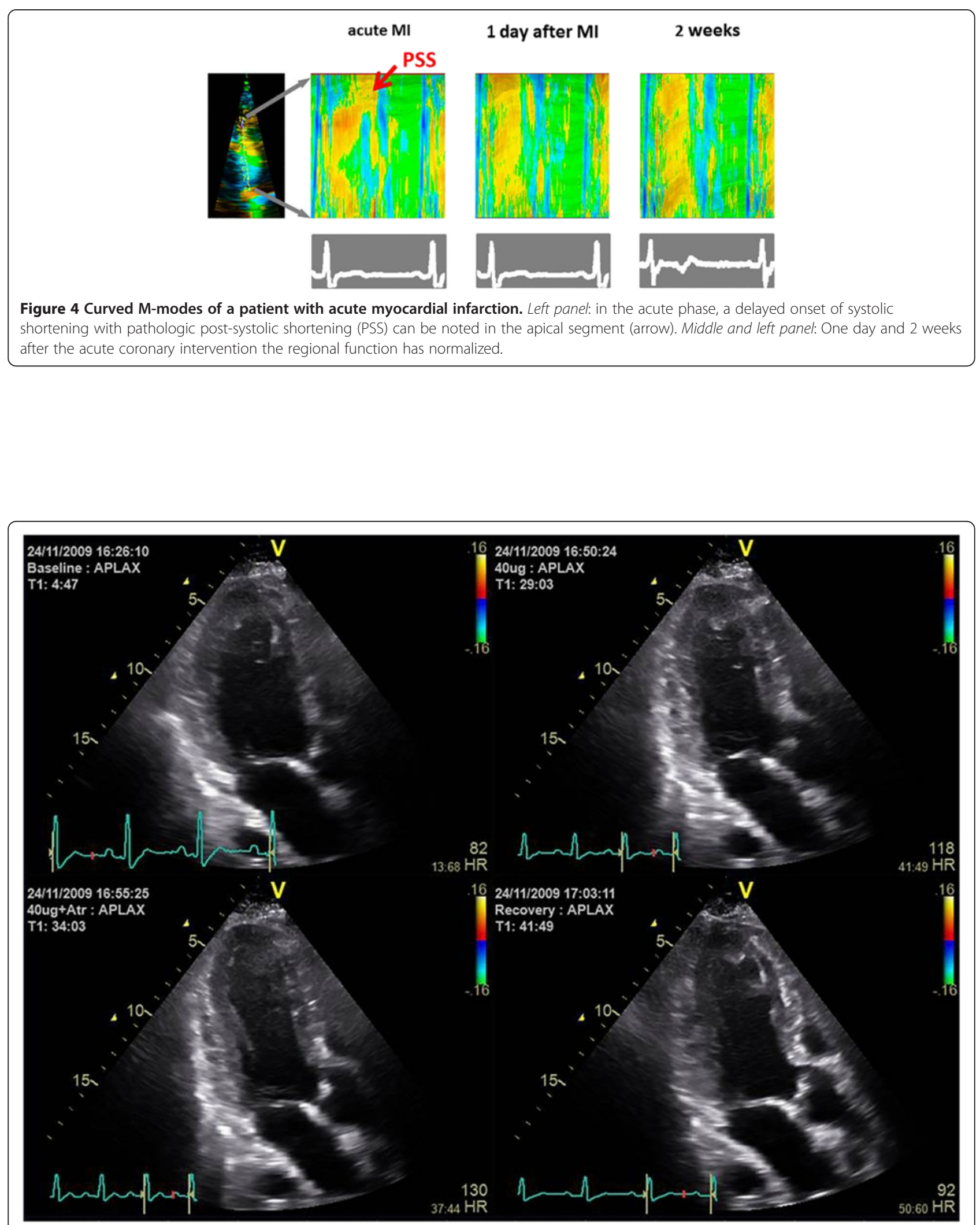

Figure 5 For the optimal visual assessment of wall motion in stress echocardiograms, a synchronized replay of the different stress stages of the examination in a quad-screen display is crucial. Note the colour bars in the image which indicate that colour tissue Doppler data have been acquired simultaneously which allow the quantification of myocardial function. 


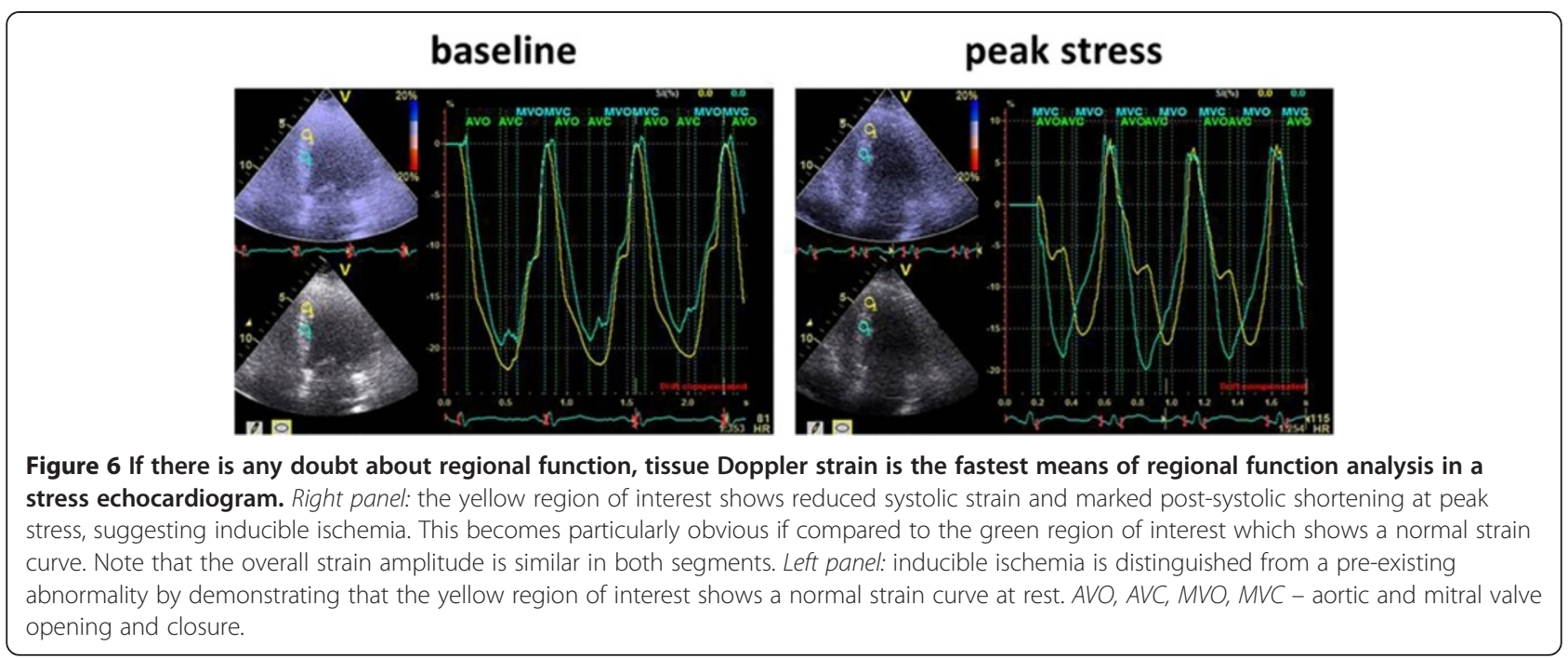

which requires training and experience [1-4]. Functional imaging can help to objectify findings and increase the diagnostic and prognostic value of the test $[23,26,27]$. Stress testing is therefore one of the most important applications of functional imaging.

\section{Data acquisition}

Tissue Doppler strain is robust for shape analysis, quickly analysable during data review and can easily deal with high heart rates due to its excellent temporal resolution. It is therefore our preferred method during stress echocardiography. We use a machine which allows the simultaneous acquisition of grey scale and colour tissue Doppler data while only the grey scale image is displayed. Care must be taken that the underlying colour Doppler sector has the size of the full image, while the frame rate should not fall far below $100 \mathrm{fps}$. We acquire apical four-, threeand two-chamber views as they allow to measure longitudinal strain in all segments. We perform stress echos according to current recommendations [19]. Dobutamine is the preferred stressor since it allows convenient image acquisition over three consecutive cycles during a breath hold even at peak stress. Bicycle stress is also possible, but makes data acquisition more challenging. As in regular stress echo examinations, the acquisition of identical image planes at each stage is crucial.

\section{Data analysis}

The classical visual assessment of wall motion in a quad-screen display of baseline and different stress stages with synchronized replay is our standard approach (Figure 5). In case of any doubt, regional strain is analyzed. This is possible "on the fly" since the underlying tissue Doppler data allow an immediate conversion into a strain map and the direct display of regional strain curves. By moving the mouse pointer over the myocardial wall, the changing shape of the strain curves is assessed with a particular focus on the detection of a relevant amount of PSS [23]. In most cases, a rough estimate of end-systole can be obtained by simultaneously

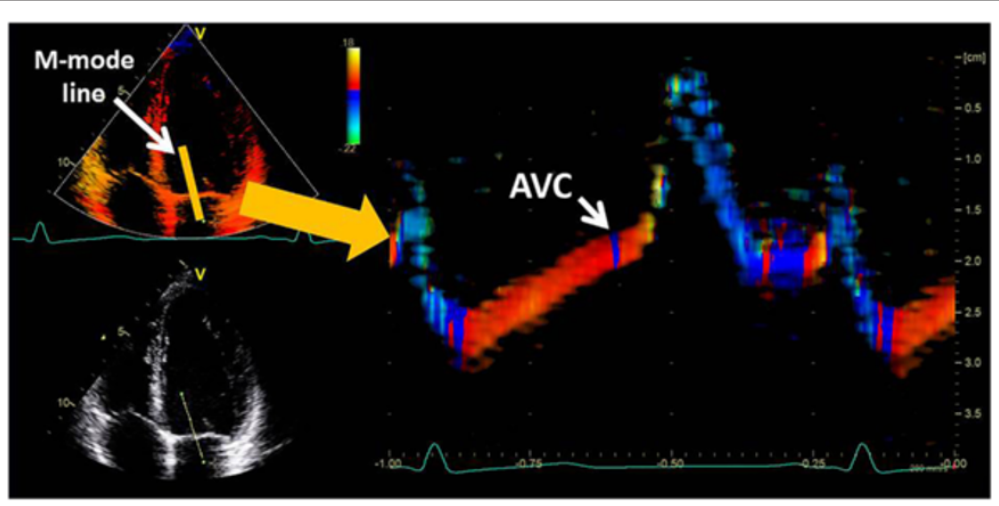

Figure 7 Timing of aortic valve closure (AVC) can be estimated from a colour M-mode across a mitral leaflet (yellow line). Note the small blue line at the systolic upstroke of the mitral leaflet contour, the beginning of which indicates aortic valve closure. 


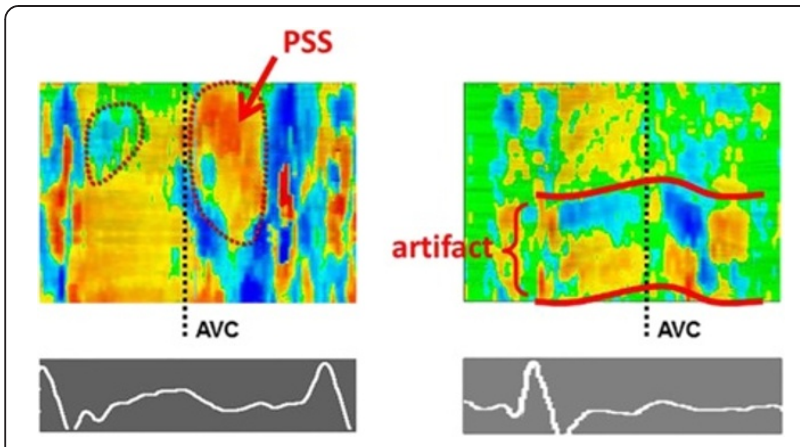

Figure 8 Distinguishing regional dysfunction and artefacts. Left panel: Regional ischemia is characterized by local changes in systole and early diastole and presents usually with a delayed onset of systolic shortening with marked post-systolic shortening (PSS) (here: apical segment). Right panel: Reverberation artefacts results in a typical band-like pattern of inverted colours around the position of the artefact which extends throughout the cardiac cycle.

showing a strain curve from a normal wall (Figure 6). If this appears not sufficiently accurate, aortic valve closure is measured in the three-chamber view directly or via the colour Doppler display of the anterior mitral valve leaflet as a reference (Figure 7) [24]. In all segments where PSS is detected at peak stress, baseline images are examined in the same way to confirm a normal strain pattern at rest. PSS is a sensitive marker of stressinduced ischemia and extends often further than a visible wall motion abnormality. A single segment with PSS is therefore not likely to represent a relevant ischemic area. If a better understanding of the PSS extend is needed, or if an artefact has to be distinguished from true pathology, a strain rate curved M-mode is a helpful tool. The yellow and blue display of shortening and lengthening allows a visual distinction of the direction of deformation. While an ischemic zone can easily be identified by its temporal and spatial distribution, artefacts are recognized by the band-like pattern of inverted colours in one position throughout the cardiac cycle (Figure 8).

\section{Summary and perspective}

Current deformation imaging software is sufficiently developed to allow fast and reliable analysis and to provide clinically helpful answers. As any quantitative imaging technique, deformation imaging relies on the assumption that pathologic processes cause functional changes and that these changes can be visualized with sufficient accuracy. Improvements in both, tissue Doppler and speckle tracking algorithms would be desirable to reduce noise and improve measurement accuracy [11]. If further developments in 2D and 3D speckle tracking, such as layer specific strain, or if the assessment of all three normal strain components in 3D data sets results in an improved diagnostic value of echocardiographic examinations remains to be determined.

From a current perspective, strain and strain rate imaging by tissue Doppler and speckle tracking are helpful tools in the clinical assessment of CAD patients and should be part of every echocardiographic examination.

\section{Competing interests}

The authors declare that they have no competing interests.

\section{Authors' contributions}

ROM, JD and JUV drafted the manuscript. JUV reviewed and approved the manuscript. All authors read and approved the final manuscript.

Received: 21 July 2014 Accepted: 1 September 2014

Published: 18 September 2014

\section{References}

1. Picano E, Lattanzi F, Orlandini A, Marini C, L'Abbate A: Stress echocardiography and the human factor: the importance of being expert. J Am Coll Cardiol 1991, 17:666-669.

2. Kvitting J-PE, Wigström L, Strotmann JM, Sutherland GR: How accurate is visual assessment of synchronicity in myocardial motion? An in vitro study with computer-simulated regional delay in myocardial motion: clinical implications for rest and stress echocardiography studies. J Am Soc Echocardiogr 1999, 12:698-705.

3. Hoffmann $R$, Lethen $H$, Marwick T, Arnese M, Fioretti P, Pingitore A, Picano E, Buck T, Erbel R, Flachskampf FA, Hanrath P: Analysis of interinstitutional observer agreement in interpretation of dobutamine stress echocardiograms. J Am Coll Cardiol 1996, 27:330-336.

4. Hoffmann R, Marwick TH, Poldermans D, Lethen $H$, Ciani R, van der Meer $P$, Tries HP, Gianfragna P, Fioretti P, Bax JJ, Katz MA, Erbel R, Hanrath P: Refinements in stress echocardiographic techniques improve interinstitutional agreement in interpretation of dobutamine stress echocardiograms. Eur Heart J 2002, 23:821-829.

5. D'hooge J, Heimdal A, Jamal F, Kukulski T, Bijnens B, Rademakers F, Hatle L, Suetens P, Sutherland GR: Regional strain and strain rate measurements by cardiac ultrasound: principles, implementation and limitations. Eur J Echocardiogr 2000, 1:154-170.

6. Mor-Avi V, Lang RM, Badano LP, Belohlavek M, Cardim NM, Derumeaux G, Galderisi M, Marwick T, Nagueh SF, Sengupta PP, Sicari R, Smiseth OA, Smulevitz B, Takeuchi M, JD T h, Vannan M, Voigt JU, Zamorano JL: Current and evolving echocardiographic techniques for the quantitative evaluation of cardiac mechanics: ASE/EAE consensus statement on methodology and indications endorsed by the Japanese Society of Echocardiography. Eur J Echocardiogr 2011, 12:167-205.

7. Galiuto L, Badano L, Fox K, Sicari R, Zamorano JL: The EAE Textbook of Echocardiography. Oxford: Oxford University Publishing; 2011.

8. Heimdal A, Støylen A, Torp H, Skjaerpe T: Real-time strain rate imaging of the left ventricle by ultrasound. J Am Soc Echocardiogr 1998, 11:1013-1019.

9. Leitman M, Lysyansky P, Sidenko S, Shir V, Peleg E, Binenbaum M, Kaluski E, Krakover R, Vered Z: Two-dimensional strain-a novel software for realtime quantitative echocardiographic assessment of myocardial function. J Am Soc Echocardiogr 2004, 17:1021-1029.

10. Wierzbowska-Drabik K, Hamala P, Roszczyk N, Lipiec P, Plewka M, Kręcki R, Kasprzak JD: Feasibility and correlation of standard 2D speckle tracking echocardiography and automated function imaging derived parameters of left ventricular function during dobutamine stress test. Int J Cardiovasc Imaging 2014, 30:729-737.

11. Voigt JU, Pedrizzetti G, Lysyansky P, Houle H, Baumann R, Pedri S, Ito Y, Abe Y, Metz S, Song J, Hamilton J, Sengupta P, Thomas JD BL: Definitions for a common standard for 2D speckle tracking echocardiography. Consensus document of the EACVI/ASE/Industry Task Force to Standardize Deformation Imaging. Eur Hear J Cardiovasc Imaging 2014, in press.

12. Heyndrickx GR, Millard RW, McRitchie RJ, Maroko PR, Vatner SF: Regional myocardial functional and electrophysiological alterations after brief coronary artery occlusion in conscious dogs. J Clin Invest 1975, 56:978-985. 
13. Jamal F, Strotmann J, Weidemann F, Kukulski T, D'hooge J, Bijnens B, Van de Werf F, De Scheerder I, Sutherland GR: Noninvasive quantification of the contractile reserve of stunned myocardium by ultrasonic strain rate and strain. Circulation 2001, 104:1059-1065.

14. Diamond GA, Forrester JS, deLuz PL, Wyatt HL, Swan HJ: Post-extrasystolic potentiation of ischemic myocardium by atrial stimulation. Am Heart J 1978, 95:204-209.

15. Weidemann F: Defining the transmurality of a chronic myocardial infarction by ultrasonic strain-rate imaging: implications for identifying intramural viability: an experimental study. Circulation 2003, 107:883-888.

16. Pfeffer MA, Braunwald E: Ventricular remodeling after myocardial infarction. Experimental observations and clinical implications. Circulation 1990, 81:1161-1172.

17. Warren SE, Royal HD, Markis JE, Grossman W, McKay RG: Time course of left ventricular dilation after myocardial infarction: influence of infarctrelated artery and success of coronary thrombolysis. J Am Coll Cardiol 1988, 11:12-19.

18. Algranati $D$, Kassab GS, Lanir Y: Why is the subendocardium more vulnerable to ischemia? A new paradigm. Am J Physiol Heart Circ Physiol 2011, 300:H1090-H1100.

19. Sicari R, Nihoyannopoulos P, Evangelista A, Kasprzak J, Lancellotti P, Poldermans D, Voigt JU, Zamorano JL: Stress Echocardiography Expert Consensus Statement-Executive Summary: European Association of Echocardiography (EAE) (a registered branch of the ESC). Eur Heart J 2009, 30:278-289.

20. Montalescot G, Sechtem U, Achenbach S, Andreotti F, Arden C, Budaj A, Bugiardini R, Crea F, Cuisset T, Di Mario C, Ferreira JR, Gersh BJ, Gitt AK, Hulot JS, Marx N, Opie LH, Pfisterer M, Prescott E, Ruschitzka F, Sabaté M, Senior R, Taggart DP, van der Wall EE, Vrints CJ, ESC Committee for Practice Guidelines, Zamorano JL, Achenbach S, Baumgartner H, Bax JJ, Bueno H: 2013 ESC guidelines on the management of stable coronary artery disease: the Task Force on the management of stable coronary artery disease of the European Society of Cardiology. Eur Heart J 2013, 34:2949-3003

21. Takigiku K, Takeuchi M, Izumi C, Yuda S, Sakata K, Ohte N, Tanabe K, Nakatani S, JUSTICE investigators: Normal range of left ventricular 2dimensional strain: Japanese Ultrasound Speckle Tracking of the Left Ventricle (JUSTICE) study. Circ J 2012, 76:2623-2632.

22. Kukulski T, Jamal F, D'Hooge J, Bijnens B, De Scheerder I, Sutherland GR: Acute changes in systolic and diastolic events during clinical coronary angioplasty: a comparison of regional velocity, strain rate, and strain measurement. J Am Soc Echocardiogr 2002, 15:1-12.

23. Voigt J-U, Exner B, Schmiedehausen K, Huchzermeyer C, Reulbach U, Nixdorff U, Platsch G, Kuwert T, Daniel WG, Flachskampf FA: Strain-rate imaging during dobutamine stress echocardiography provides objective evidence of inducible ischemia. Circulation 2003, 107:2120-2126.

24. Voigt J-U, Lindenmeier G, Exner B, Regenfus M, Werner D, Reulbach U, Nixdorff U, Flachskampf FA, Daniel WG: Incidence and characteristics of segmental postsystolic longitudinal shortening in normal, acutely ischemic, and scarred myocardium. J Am Soc Echocardiogr 2003, 16:415-423.

25. Mele D, Pasanisi G, Capasso F, De Simone A, Morales M-A, Poggio D, Capucci A, Tabacchi B, Sallusti L, Ferrari R: Left intraventricular myocardial deformation dyssynchrony identifies responders to cardiac resynchronization therapy in patients with heart failure. Eur Heart J 2006, 27:1070-1078

26. Ng AC, Sitges M, Pham PN, Tran da T, Delgado V, Bertini M, Nucifora G, Vidaic J, Allman C, Holman ER, Bax JJ, Leung DY: Incremental value of 2dimensional speckle tracking strain imaging to wall motion analysis for detection of coronary artery disease in patients undergoing dobutamine stress echocardiography. Am Heart J 2009, 158:836-844.

27. Ingul CB, Stoylen A, Slordahl SA, Wiseth R, Burgess M, Marwick TH: Automated analysis of myocardial deformation at dobutamine stress echocardiography: an angiographic validation. J Am Coll Cardiol 2007, 49:1651-1659.

doi:10.1186/1476-7120-12-38

Cite this article as: Mada et al:: Tissue Doppler, Strain and Strain Rate in ischemic heart disease "How I do it". Cardiovascular Ultrasound 2014 12:38

\section{Submit your next manuscript to BioMed Central and take full advantage of:}

- Convenient online submission

- Thorough peer review

- No space constraints or color figure charges

- Immediate publication on acceptance

- Inclusion in PubMed, CAS, Scopus and Google Scholar

- Research which is freely available for redistribution
C Biomed Central 